\title{
Impact of Campylobacter spp. on the Integrity of the Porcine Gut
}

\author{
Alexandra Rath ${ }^{1, *} *$ D, Silke Rautenschlein ${ }^{2}$, Janina Rzeznitzeck ${ }^{2}$, Gerhard Breves ${ }^{3}$, Marion Hewicker-Trautwein ${ }^{4}$, \\ Karl-Heinz Waldmann ${ }^{1,+}$ and Alexandra von Altrock ${ }^{1}$
}

check for

updates

Citation: Rath, A.; Rautenschlein, S.;

Rzeznitzeck, J.; Breves, G.;

Hewicker-Trautwein, M.; Waldmann,

K.-H.; von Altrock, A. Impact of

Campylobacter spp. on the Integrity of

the Porcine Gut. Animals 2021, 11,

2742. https://doi.org/10.3390/

ani11092742

Received: 27 July 2021

Accepted: 16 September 2021

Published: 19 September 2021

Publisher's Note: MDPI stays neutral with regard to jurisdictional claims in published maps and institutional affiliations.

Copyright: (c) 2021 by the authors. Licensee MDPI, Basel, Switzerland. This article is an open access article distributed under the terms and conditions of the Creative Commons Attribution (CC BY) license (https:// creativecommons.org/licenses/by/ $4.0 /)$.
1 Clinic for Swine and Small Ruminants, Forensic Medicine and Ambulatory Service, University of Veterinary Medicine Hannover, Foundation, 30173 Hannover, Germany; Karl-Heinz.Waldmann@tiho-hannover.de (K.-H.W.); Alexandra.von.Altrock@tiho-hannover.de (A.v.A.)

2 Clinic for Poultry, University of Veterinary Medicine Hannover, Foundation, 30559 Hannover, Germany; Silke.Rautenschlein@tiho-hannover.de (S.R.); Janina.Rzeznitzeck@tiho-hannover.de (J.R.)

3 Institute for Physiology and Cell Biology, University of Veterinary Medicine Hannover, Foundation, 30173 Hannover, Germany; Gerhard.Breves.iR@tiho-hannover.de

4 Department of Pathology, University of Veterinary Medicine Hannover, Foundation, 30559 Hannover, Germany; Marion.Hewicker-Trautwein@tiho-hannover.de

* Correspondence: Alexandra.Rath@tiho-hannover.de

+ Valuable contribution to this paper before he departed.

Simple Summary: Campylobacteriosis is recognised as a leading food-borne zoonotic enteric disease of humans, mainly caused by Campylobacter jejuni, and to a minor extent by C. coli. In general, pigs are symptomless carriers primarily of C. coli, but may also harbour C. jejuni. In a swine infection model, weaned piglets were intragastrically inoculated with C. coli (ST-5777; $n=8)$, with C. jejuni (ST-122; $n=10)$, or with both strains $(n=8)$ and 11 piglets served as control. The health status was monitored and the influence on the intestinal barrier was investigated using the Ussing chamber technique and histological examinations. After inoculation, no clinical manifestations were noted. No gross lesions were observed during dissection four weeks post inoculation, and no pathohistological changes were detected in the intestinal mucosal sections. On the other hand, in the caecum of $C$. jejuni mono-inoculated pigs, we recognized an impact on transepithelial transport processes. We observed an increased $\mathrm{Cl}^{-}$secretion by using the Ussing chamber technique.

Abstract: Campylobacter (C.) is the most common food-borne zoonosis in humans, which mainly manifests with watery to bloody diarrhoea. While C. jejuni is responsible for most cases of infection, C. coli is less frequently encountered. The object of the study was to prove the clinical impact of mono- and co-colonisation of $C$. coli and C. jejuni on weaned piglets in an infection model and to investigate the impact on transepithelial transport processes in the jejunum and caecum. At an age of eight weeks, eight pigs were infected with C. coli (ST-5777), 10 pigs with C. jejuni (ST-122), eight pigs with both strains, and 11 piglets served as control. During the four-week observation period, no clinical signs were observed. During dissection, both strains could be isolated from the jejunum and the caecum, but no alteration of the tissue could be determined histopathologically. Mono-infection with C. jejuni showed an impact on transepithelial ion transport processes of the caecum. An increase in the short circuit current $\left(\mathrm{I}_{\mathrm{sc}}\right)$ was observed in the Ussing chamber resulting from carbachol- and forskolin-mediated $\mathrm{Cl}^{-}$secretion. Therefore, we speculate that caecal colonisation of $C$. jejuni might affect the transport mechanisms of the intestinal mucosa without detectable inflammatory reaction.

Keywords: pig; intestine; Campylobacter; experimental infection; Ussing chamber

\section{Introduction}

Campylobacter (C.) has replaced Salmonella as the most common human diarroheal pathogen in all developing and non-developing countries [1,2]. In 2019, 61,526 cases 
were registered in Germany [3]. While it is part of the intestinal flora without clinical influence [4] in a large number of mammals and birds, the bacterium frequently triggers acute enteritis in humans [1,2]. This enteritis is primarily associated with Campylobacter jejuni $(73 \%)$ and mainly transmitted by poultry meat, followed by C. coli $(10 \%)$ with pork as a potential vector [3]. The prevalence of Campylobacter in pig herds is estimated to be as high as $100 \%$ [4,5], where $C$. coli distinctly predominates over $C$. jejuni [6]. In most cases, the infection is transmitted faecal-orally from sow to piglet [7].

In general, Campylobacter is considered a commensal of the intestinal microbiota in pigs, but gnotobiotic- and colostrum-deprived young piglets developed clinically manifested enteritis after inoculation with C. jejuni [8-11]. Immune reactions and lesions have also been described in broilers, hens, and turkeys after infection [12,13]. Host factors, especially the composition of the mucus layer, as well as microbial characteristics, such as the specific nutrient metabolism, seem to influence the outcome of an infection [14-16].

The pathogenicity of the bacterium is mainly due to its motility, chemotactic orientation, adhesion and invasion ability, and toxin production [17].

In cell cultures (T84, Caco-2 cells), increased permeability of the intestinal mucosa, decreased transepithelial resistance, and alteration of tight junctions were observed after infection with Campylobacter spp. [18,19]. In addition, studies of the barrier properties of the chicken intestine using the Ussing chamber revealed changes in the intestinal barrier despite the absence of symptoms. After adding histamine, the infected group showed decreased ion transport, indicating decreased nutrient uptake. Furthermore, the infection caused intestinal histomorphological changes in the jejunum, characterised primarily by shortened villi and decreased crypt depth [20,21]. In this study, glucose, forskolin, and carbachol were used to investigate transport mechanisms in the Ussing chamber. The addition of glucose is used to examine sodium-glucose-linked transporter 1 (SGLT1) in jejunal tissue [22,23]. Forskolin activates cAMP-driven $\mathrm{Cl}^{-}$secretion [24], while carbachol (used only in the caecum) acts on Ca-driven secretion [25-27]. Histological examinations were performed after haematoxylin and eosin (H\&E) staining.

Comparable investigations on the gut integrity and function of the gut epithelium of swine after Campylobacter colonisation do not yet exist for the pig and were therefore performed in the present study.

\section{Materials and Methods}

\subsection{Campylobacter Strains and Inoculum Preparation}

Two different Campylobacter strains were used for this experiment: C. coli: ST5777/CT828 and C. jejuni: ST122/CT206. Both strains were isolated from poultry and had been used in a previous study [28]. The genotypes, characterised by multilocus sequence typing (MLST), had previously been isolated several times in association with human disease (http: / / pubmlst.org/campylobacter/, accessed on 18 May 2021). The C. coli strain was isolated from a sporadic case of gastroenteritis in humans in Luxembourg in 2012. The C. jejuni strain was isolated from faeces of a human case associated with Guillain-Barré syndrome. It has also been found in numerous cases in the United States, the Netherlands, and Germany in association with gastroenteritis in humans. Most recently, the strain was isolated in one case of systemic disease in the United Kingdom.

Different laboratory-induced antibiotic resistance patterns of the strains enabled differentiation when grown on agar supplemented with the corresponding antibiotic substance. The C. coli ST-5777 strain is resistant against nalidixic acid, and C. jejuni ST-122 against streptomycin.

For the infection experiment, nutrient broth (nutrient broth no. 2, CM0067, OXOID/Thermo Scientific Inc., Waltham, MA, USA) was enriched with bacterial colonies of the respective Campylobacter spp. $48 \mathrm{~h}$ before infection and incubated in a micro-aerophilic atmosphere $\left(5 \% \mathrm{O}_{2}, 10 \% \mathrm{CO}_{2}\right.$ and $85 \% \mathrm{~N}_{2}$ ) with Thermo Scientific ${ }^{\mathrm{TM}}$ Oxoid $^{\mathrm{TM}}$ CampyGen $^{\mathrm{TM}}$ (Thermo Scientific Inc.) at $37.4^{\circ} \mathrm{C}$. An infective dose of $10^{8}$ colony-forming units (cfu) per animal in 
$10 \mathrm{~mL}$ broth was targeted. The actual infectious dose was determined subsequently by a dilution series.

\subsection{Animals and Experimental Set-Up}

In total, 37 (21 male, 16 female) crossbred piglets ((Danish Landrace $\times$ German Large White) $\times$ German Landrace) were used for the experiment. They were derived by Caesarean section to exclude a Campylobacter field colonisation and raised in isolation units. The pigs were housed and treated in accordance with the German Animal Welfare Act which complies with the German Research Council's criteria and the EC Directive 2010/63/EU for animal experiments. The absence of Campylobacter spp. was ensured by regular rectal swabs. Strict hygiene standards were established to avoid transmission of Campylobacter between units after infection.

CulinaMilk $^{\circledR}$ (H. Bröring GmbH \& Co. KG, Dinklage, Germany) was used as milk replacer. After weaning in the fifth week of life, the pigs were fed twice daily with a conventional rearing diet (Deuka GmbH \& Co. KG, Düsseldorf, Germany) and had access to drinking water ad libitum. The piglets were injected with $2 \mathrm{~mL}$ iron dextrane (Ursoferran ${ }^{\circledR}$ $100 \mathrm{mg} / \mathrm{mL}$, Serumwerk Bernburg AG, Bernburg, Germany) subcutaneously (s.c.) on their third day of life.

The piglets were randomly divided into four different groups (Table 1) and inoculated with the respective Campylobacter strain in week eight. Hereafter, the control group is referred to as Group 0, the group infected with C. coli is called Group 1, and the group infected with $C$. jejuni is called Group 2. In addition, the group infected with both strains is called Group 3.

Table 1. Infection scheme of the animal groups.

\begin{tabular}{cccc}
\hline Group & Number of Piglets & Inoculation & $\begin{array}{c}\text { Inoculation } \\
\text { Dose/10 } \mathbf{~ m L ~ ( c f u ) ~}\end{array}$ \\
\hline 0 & 11 & 10 mL nutrient broth & 0 \\
1 & 8 & $10 \mathrm{~mL}$ nutrient broth with C. coli & $1 \times 10^{8}$ \\
2 & 10 & $10 \mathrm{~mL}$ nutrient broth with C. jejuni & $5 \times 10^{9}$ \\
3 & 8 & $10 \mathrm{~mL}$ nutrient broth with C. coli & $1.9 \times 10^{10}$ C. Coli \\
& & $+10 \mathrm{~mL}$ nutrient broth with C. jejuni & $7.7 \times 10^{8}$ C. jejuni \\
\hline
\end{tabular}

In the eighth week of life, the animals were anaesthetized with azaperone $(2 \mathrm{mg} / \mathrm{kg}$ body weight Stresnil ${ }^{\circledR}$, Elanco ${ }^{\mathrm{TM}}$, Elanco Inc., Greenfield, IN, USA) and ketamine ( $20 \mathrm{mg} / \mathrm{kg}$ body weight Ketamin ${ }^{\circledR}, \mathrm{CP}-\mathrm{Pharma}{ }^{\circledR}, \mathrm{CP}-\mathrm{Pharma}$ Handelsgesellschaft GmbH, Burgdorf, Germany) and inoculated by intragastric application via a stomach tube $(\mathrm{CH} 12$, B. Braun Melsungen AG, Melsungen, Germany), according to the scheme in Table 1.

During the experiment, the pigs underwent daily monitoring including evaluation of the general health condition and rectal measurement of body temperature in the morning. If the rectal temperature rose above $40^{\circ} \mathrm{C}$, the temperature was rechecked after $12 \mathrm{~h}$. If it was still elevated thereafter, the piglets were treated orally with Metacam ${ }^{\circledR}$ (Meloxicam, $15 \mathrm{mg} / \mathrm{mL} ; 0.4 \mathrm{mg} / \mathrm{kg}$ body weight, Boehringer Ingelheim Vetmedica $\mathrm{GmbH}$, Ingelheim, Germany).

At necropsy four weeks after inoculation, the animals had an average body weight of $30.9 \pm 5.6 \mathrm{~kg}$.

\subsection{Sampling and Cultivation of Campylobacter Strains from Faeces and Ingesta}

During the experimental period, rectal swabs were collected both before and after infection to demonstrate the absence of Campylobacter spp. and to confirm intestinal colonisation after infection, respectively.

All animals were stunned by captive bolt shot and killed by exsanguination in the 13th week of life (four weeks post-inoculation with Campylobacter spp.). Immediately thereafter, 
the abdomen was opened by a midline incision and the intestinal tract was removed. During dissection, the intestinal tract was examined macroscopically for pathological abnormalities.

The first three metres of jejunum were discarded, and the following $30 \mathrm{~cm}$ were removed. Additionally, the middle part of the caecum was excised for Ussing chamber experiments.

Previous experiments showed that Campylobacter spp. colonise mainly in these two intestinal sections [28]. Therefore, the experiments were carried out on the jejunum and caecum using the Ussing chamber.

The intestinal segments were rinsed with cold physiological saline solution $\left(4{ }^{\circ} \mathrm{C}, 0.9 \%\right.$ $\mathrm{NaCl}(w / v))$ to remove ingesta and afterwards stored in cooled serosal buffer solution (Table 2) for Ussing chamber experiments. After longitudinal incision of the jejunum along the mesenteric border, the mucosa was stripped of the underlying muscle layers. The tissue from the caecum was also opened and the mucosa separated. The specimens were then clamped in the Ussing chambers.

Table 2. Protocol for the preparation of buffer solutions for the Ussing chamber procedure (concentration in $\mathrm{mmol} / \mathrm{L})$.

\begin{tabular}{cccc}
\hline Chemicals & $\begin{array}{c}\text { Serosal Side [mmol/L] } \\
\text { (Both Epithelia) }\end{array}$ & $\begin{array}{c}\text { Mucosal Side [mmol/L] } \\
\text { (Jejunal Epithelia) }\end{array}$ & $\begin{array}{c}\text { Mucosal Side [mmol/L] } \\
\text { (Caecal Epithelia) }\end{array}$ \\
\hline $\mathrm{NaCl}$ & 113.6 & 113.6 & 53.6 \\
$\mathrm{KCl}$ & 5.4 & 5.4 & 5.4 \\
$\mathrm{HCl}$ & 0.2 & 0.2 & 0.2 \\
$\mathrm{MgCl}_{2}$ & 1.2 & 1.2 & 1.2 \\
$\mathrm{CaCl}_{2}$ & 1.2 & 1.2 & 1.2 \\
$\mathrm{NaHCO}_{3}$ & 21.0 & 21.0 & 21.0 \\
$\mathrm{Na}_{2} \mathrm{HPO}_{4}$ & 1.5 & 1.5 & -5 \\
glucose $_{\text {mannitol }}$ & 10.0 & - & 2.0 \\
HEPES & 2.0 & 2.0 & 10.0 \\
Na-gluconate & 7.0 & 20.0 & 6.0 \\
NaOH & 6.0 & - & - \\
Na-acetate & - & - & 36.0 \\
Na-propionate & - & - & 15.0 \\
Na-butyrate & - & & 9.0 \\
\hline
\end{tabular}

1 (4-(2-hydroxyethyl)-piperazine-1-ethanesulfonic acid).

For the histological examinations, samples were taken from the duodenum, jejunum, ileum, caecum and colon. The sampling sites of the jejunum and caecum were adjacent to the samples taken for the Ussing chamber. Intestinal samples were rinsed with physiological saline solution and placed in $4 \%(w / v)$ phosphate buffered formalin for at least $48 \mathrm{~h}$.

For the microbiological examination, faecal and intestinal samples (intestinal mucosa + intestinal contents) were placed in a tube filled with $10 \mathrm{~mL}$ Preston broth for enrichment and incubated for $48 \mathrm{~h}$ at $37.4{ }^{\circ} \mathrm{C}$ in a micro-aerophilic atmosphere $\left(5 \% \mathrm{O}_{2}, 10 \% \mathrm{CO}_{2}\right.$ and $85 \% \mathrm{~N}_{2}$ ). After this time, the enrichment was spread onto modified charcoal cefoperazonedeoxycholate agar plates (mCCDA, Thermo Scientific Inc., Waltham, MA, USA) and incubated again for $48 \mathrm{~h}$ as described above (the procedure can be seen in Figure S1). The CCDA agar was enriched with the corresponding antibiotic (C. coli = nalidixic acid; C. jejuni = streptomycin; detailed ingredients can be found in Tables S1-S3). Subsequently, the presence of Campylobacter-specific colonies was examined, and a native smear was performed if the results were questionable. In addition, random samples from Groups 1 and 2 were spread on the CCDA agar enriched with the other antibiotic in order to exclude cross-contamination of the mono-infection groups.

\subsection{Set-Up for Ussing Chamber Technique}

Stripped jejunal and caecal mucosal tissues were mounted in the Ussing chambers. Three chambers were used per intestinal segment and per animal (exposed serosal area of $1.00 \mathrm{~cm}^{2}$ ). By mounting the tissues between the two halves of the Ussing chamber, a 
barrier was formed between the serosal and mucosal compartment, each of which were filled with $10 \mathrm{~mL}$ buffer. For the serosal side, the same buffer was used for the jejunum and caecum. On the mucosal side, different buffers were used for the two intestinal segments. The buffer composition is shown in Table 2.

All buffer solutions had an osmolarity of $297 \mathrm{mosmol} \mathrm{kg}{ }^{-1}$, were heated to $37^{\circ} \mathrm{C}$, and were continuously aerated with carbogen. The $\mathrm{pH}$ value ranged between 7.45 and 7.47.

All chemicals for the buffer solutions were obtained from Merck KGaA, Darmstadt, Germany, except mannitol, which was purchased from Sigma-Aldrich Inc., St. Louis, MO, USA, and HEPES, which was purchased from Carl Roth GmbH + Co.KG, Karlsruhe, Germany.

After filling the chambers with buffer solutions, they were connected to computercontrolled voltage clamps (K. Mussler Scientific Instruments, Aachen, Germany) through which the transepithelial potential difference $\left(\mathrm{PD}_{\mathrm{t}}\right)$, tissue conductance $\left(\mathrm{G}_{\mathrm{t}}\right)$, and short circuit current $\left(\mathrm{I}_{\mathrm{sc}}\right)$ were measured. The experiment was performed under short-circuited conditions.

Firstly, the tissues were equilibrated for $30 \mathrm{~min}$ after attaching the voltage clamps and filling in the buffers. After the 30-min equilibration phase, the voltage was clamped to zero. The further experiment was performed in accordance with two different protocols, respectively for the tissue from the jejunum and caecum.

According to the first protocol, the mucosal glucose concentration of the jejunal tissues was adjusted to $10 \mathrm{mmol} / \mathrm{L}$ after equilibration. In order to avoid transepithelial osmotic gradients, this was compensated by adding mannitol to the serosal side. After an incubation period of $30 \mathrm{~min}, 5 \times 10^{-6} \mathrm{M}$ forskolin $(1 \mu \mathrm{L}$, serosal $)$ was added.

The second protocol was applied to the caecal tissues: $10^{5} \mathrm{M}$ carbachol $(10 \mu \mathrm{L}$, serosal $)$ was added, incubated for another $30 \mathrm{~min}$ and then $5 \times 10^{-6} \mathrm{M}$ forskolin $(1 \mu \mathrm{L}$, serosal $)$ was added. Forskolin and carbachol were obtained from Sigma-Aldrich Inc., St. Louis, MO, USA. After adding forskolin, another $30 \mathrm{~min}$ incubation period was performed before the experiment was terminated.

\subsection{Histological Investigation}

Tissue samples from duodenum, jejunum, ileum, caecum, and colon were stored in formalin solution ( $100 \mathrm{~mL}$ formaldehyde $37 \%, 900 \mathrm{~mL}$ bidest, $4 \mathrm{~g} \mathrm{NaH} \mathrm{NO}_{4} \mathrm{H}_{2} \mathrm{O}, 6.5 \mathrm{~g}$ $\mathrm{Na}_{2} \mathrm{HPO}_{4}$ ) for at least $48 \mathrm{~h}$. Post-fixation, tissue drainage and embedding of the fixed tissue with paraffin was performed in the Shandon Pathcentre ${ }^{\circledR}$ Tissue Processor (Thermo Scientific Inc., Waltham, MA, USA). The samples were then poured into paraffin wax blocks at a paraffin pouring station (TES 4004 Tissue Embedding Station, PFM, Cologne, Germany). Tissue sections with a thickness of $2 \mu \mathrm{m}$ were prepared from the paraffin wax blocks on a slide microtome (2646, Reichert \& Jung GmbH, Heidelberg, Germany). The sections were placed in a water bath at $40{ }^{\circ} \mathrm{C}$, applied to Menzel Superfrost ${ }^{\circledR}$ Ultra Plus slides (Thermo Scientific Inc.) and dried for at least $24 \mathrm{~h}$ at room temperature.

The sections were dewaxed, dehydrated and stained automatically with haematoxylinand eosin (H\&E) (Varistan 24-2, Shandon GmbH, Frankfurt, Germany) in accordance with a protocol (Table 3). Subsequently, the sections were covered with ROTI ${ }^{\circledR}$ Mount and coverglass, dried for at least $24 \mathrm{~h}$ and examined microscopically.

For the histological specimens, a scoring key of 1-5 was used for semiquantitative analysis of the inflammatory infiltrate for microscopic examination. Specimens were graded according to the degree of neutrophilic and increased lymphoplasmacytic cell infiltration, and possible differences between groups were evaluated $(1=$ slight infiltration, $2=$ mild infiltration, $3=$ moderate infiltration, $4=$ marked infiltration, $5=$ severe infiltration). 
Table 3. Protocol for staining the histological samples.

\begin{tabular}{ccc}
\hline Process & Chemicals & Time \\
\hline \multirow{3}{*}{ Dewaxing and rehydration } & N-butyl acetate & $2 \times 10 \mathrm{~min}$ \\
& Isopropanol 100\% & $5 \mathrm{~min}$ \\
& Isopropanol 96\% & $5 \mathrm{~min}$ \\
& Isopropanol 70\% & $5 \mathrm{~min}$ \\
& Isopropanol 50\% & $5 \mathrm{~min}$ \\
\hline Hemalaun staining & Hemalaun Usage Solution & $10 \mathrm{~min}$ \\
\hline \multirow{2}{*}{ Washing } & Running tap water & $10 \mathrm{~min}$ \\
& Distilled water & $2 \mathrm{~min}$ \\
\hline Eosin staining & Eosin working solution & $5 \mathrm{~min}$ \\
\hline Washing & Distilled water & $2 \times 30 \mathrm{~s}$ \\
\hline \multirow{2}{*}{ Dehydration } & Isopropanol 70\% & $30 \mathrm{~s}$ \\
& Isopropanol 70\% & $2 \mathrm{~min}$ \\
& Isopropanol 70\% & $2 \mathrm{~min}$ \\
& N-butyl acetate & $10 \mathrm{~min}$ \\
\hline
\end{tabular}

\subsection{Dry Matter Determination of Ingesta (Caecum)}

To determine the dry matter (DM) of ingesta from the caecum, approximately $1 \mathrm{~g}$ of the sample (E) was weighed into a metal crucible (T1) and then dried at $103{ }^{\circ} \mathrm{C}$ for a period of at least four hours in a drying oven.

The samples were allowed to cool in a desiccator before the porcelain crucibles were weighed again (T2). Ten samples were treated per group.

The following formula was used to determine the dry matter content.

$$
\text { Calculating of } \mathrm{DM}(\mathrm{g} / \mathrm{kg})=\left[\frac{T 1-T 2}{E}\right] \times 1000
$$

\subsection{Data Analysis and Statistics}

Results from the Ussing chamber experiment were expressed as the mean value \pm standard deviation (MW $\pm \mathrm{SD}$ ) of the single values of the three chambers used per bowel segment. For the calculation of $\Delta \mathrm{I}_{\mathrm{sc}}$, the maximum changes after adding the respective substance were used. The statistical analysis for the results of the Ussing chamber, histological samples and dry matter determination was performed with a one-way ANOVA and the post-hoc Dunnetts $t$-test using SAS v. 9.1 (SAS Inst. Inc., Cary, NC, USA).

The differences were assumed to be statistically significant if $p \leq 0.05$.

\section{Results}

3.1. Clinical and Microbiological Findings during the Test Period and Macroscopic Findings in the Section

No abnormalities in the general condition of the animals were observed during the experimental period. Diarrhoea or increased internal body temperature did not occur (Table S4). Faecal samples of the control group (Group 0) remained Campylobacter negative throughout the trial. In the infected groups, the respective strains could be detected in the faeces as early as two days after infection (p. inf.) in some cases, but reliably seven days after inoculation. In Group 2, the detection rate decreased slightly again after day 7 (Table 4). Cross infection with the other Campylobacter strain was not detected in Groups 1 and 2.

On dissection, there were no macroscopic changes to the intestinal tract, liver, or spleen. 
Table 4. Percentage of positive samples in weekly faecal sampling for detection of the inoculated Campylobacter strain before dissection over a four-week period (Group 1: $n=8$; Group 2: $n=10$; Group 3: $n=8)$.

\begin{tabular}{ccccc}
\hline \multirow{2}{*}{ Days p. inf. } & Group 1 (\%) & Group 2 (\%) & \multicolumn{2}{c}{ Group 3 (\%) } \\
\cline { 4 - 5 } & & & C. coli & C. jejuni \\
\hline 2 & 87.5 & 30 & 25 & 37.5 \\
14 & 100 & 100 & 100 & 100 \\
21 & 100 & 90 & 100 & 75 \\
& 100 & 70 & 100 & 100 \\
\hline
\end{tabular}

\subsection{Distribution of Campylobacter spp. in Different Intestinal Segments}

Cultural investigation of the gut demonstrated different detection frequencies of the Campylobacter strains in the intestinal sections (Table 5).

Table 5. Isolation frequency of Campylobacter spp. in different intestinal sections after dissection in the twelfth week of life. C. coli mono-infection in Group 1; C. jejuni mono-infection in Group 2; co-infection divided into detection of C. jejuni and C. coli (Group 1: $n=8$; Group 2: $n=10$; Group 3: $n=8)$.

\begin{tabular}{ccccc}
\hline \multirow{2}{*}{ Intestinal Section } & Group 1 (\%) & Group 2 (\%) & \multicolumn{2}{c}{ Group 3 (\%) } \\
\cline { 4 - 5 } & & & C. coli & C. jejuni \\
\hline Duodenum & 0 & 40 & 0 & 62.5 \\
Jejunum & 25 & 100 & 12.5 & 100 \\
Ileum & 100 & 100 & 12.5 & 100 \\
Caecum & 100 & 100 & 100 & 100 \\
Colon & 100 & 100 & 100 \\
\hline
\end{tabular}

C. coli as well as C. jejuni could be reisolated from all samples from the caecum and colon. This also applied for mono- and co-infection (Groups 1-3).

Only $C$. jejuni was found in the duodenum. In Group 2, $40 \%(n=4)$ of the samples were positive, while in Group 3, 62.5\% $(n=5)$ were positive. C. coli was not detected in the duodenum in either mono- or co-infection.

C. jejuni could be isolated from the jejunum samples for Group 3 in all pigs. However, only $12.5 \%$ of the samples showed C. coli $(n=1)$. Moreover, in the mono-infected pigs, the detection of $C$. jejuni in the jejunum was higher (Group 2; 70\%; $n=7$ ) than that of $C$. coli (Group $1 ; 25 \% ; n=2$ ).

C. jejuni was detected in the ileum of all animals in Groups 2 and 3. In contrast, the identification of $C$. coli showed a difference between mono- and co-infection. While $C$. coli was detected in the ileum of all pigs in Group 1, only $12.5 \%$ of the animals in Group 3 were positive $(n=1)$.

For Group 0, the Campylobacter negative status was confirmed by the negative results of the microbiological investigation of all intestinal sections.

\subsection{Basal, Glucose-Induced and Forskolin-Induced Short-Circuit Currents ( $\left.I_{s c}\right)$ in Jejunal Epithelia}

After equilibration, the basal values for $\mathrm{I}_{\mathrm{sc}}$ were at a similar level in all four groups (Figure 1a). An increase in $\mathrm{I}_{\mathrm{sc}}$ could be measured after adding glucose and forskolin in all groups (Figure 1a) without a statistically significant difference between them $(p>0.05)$. The course of short-circuit currents and tissue conductance during the experimental period in the jejunum in an animal of the control group (Group 0 ) is exemplarily shown in Figure 2. The time course was similar for animals in the infected groups (all values can be found in Table S5). 


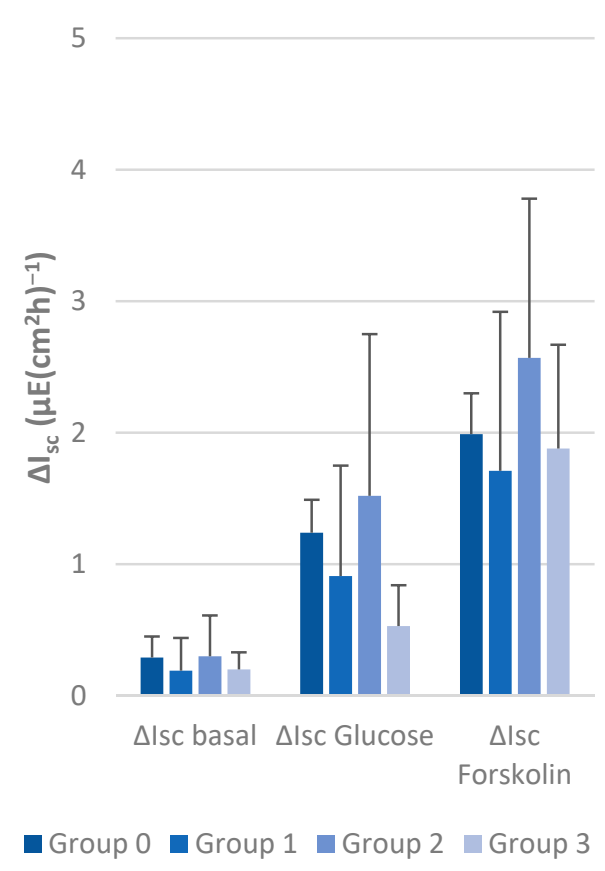

(a)

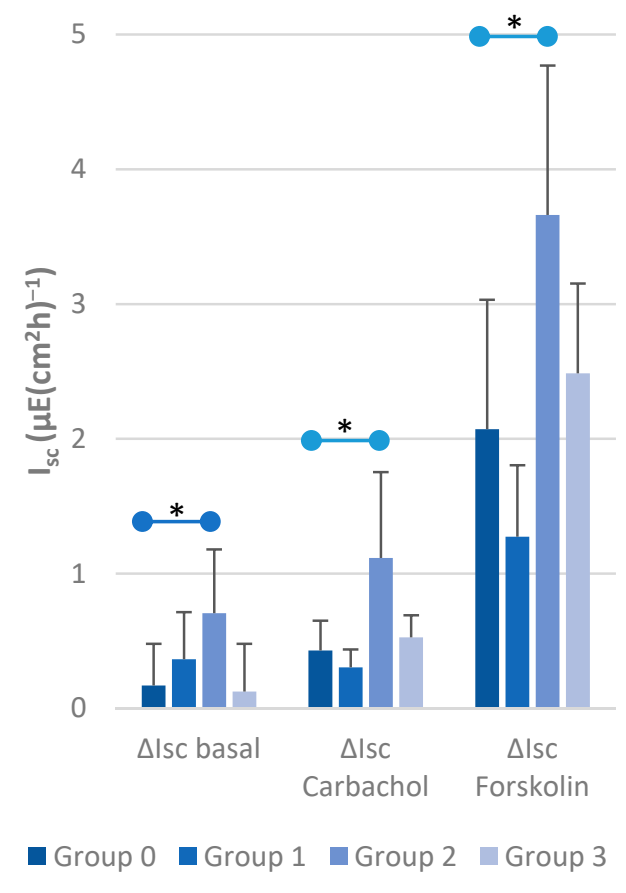

(b)

Figure 1. Basal short-circuit currents and $I_{\mathrm{sc}}$ changes of jejunal and caecal epithelia after adding glucose and forskolin. (a) Measurements of the Ussing chamber experiment with jejunal epithelia. Indicated are the basal short-circuit currents and the changes after adding $10 \mathrm{mmol}$ glucose $\left(100 \mu \mathrm{L}\right.$, mucosal) and $5 \times 10^{-6} \mathrm{M}$ forskolin $(1 \mu \mathrm{L}$, serosal). (b) Measurements of the Ussing chamber experiment with caecal epithelia. Indicated are the basal short-circuit currents and the changes after adding $10^{5} \mathrm{M}$ carbachol $(10 \mu \mathrm{L}$, serosal $)$ and $5 \times 10^{-6} \mathrm{M}$ forskolin $(1 \mu \mathrm{L}$, serosal); statistically significant values are marked with * $(p<0.05)$.

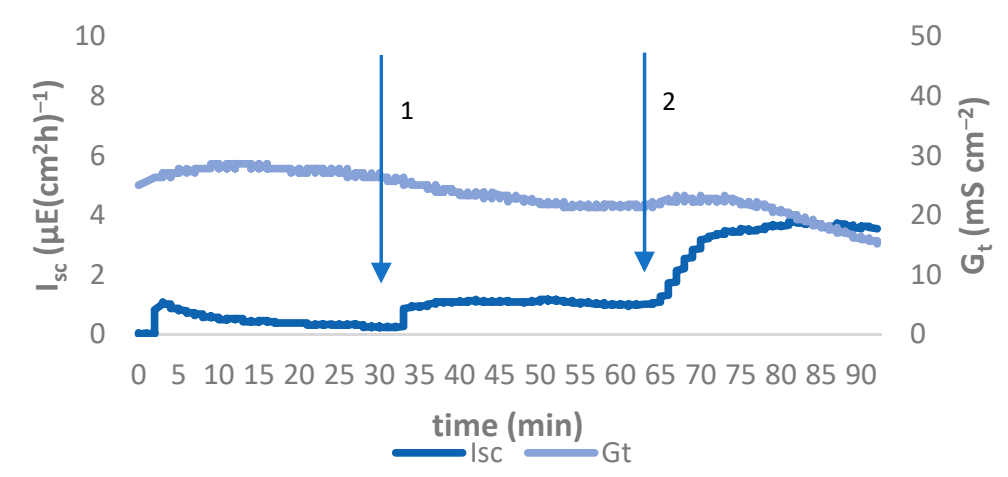

Figure 2. Typical time course of $\mathrm{I}_{\mathrm{sc}}$ and $\mathrm{G}_{\mathrm{t}}$ of jejunal epithelium using Ussing chamber experiment of a pig in Group 0. Arrows indicate addition of pharmaceuticals: 1 glucose (mucosal) + mannitol (serosal), 2 forskolin (serosal).

\subsection{Basal, Carbachol-Induced and Forskolin-Induced Short-Circuit Currents $\left(I_{S C}\right)$ in Caecal Epithelia}

Between Group 1, Group 3, and the control group (Group 0), no statistical differences in the $\mathrm{I}_{\mathrm{sc}}$ of the caecal epithelia could be demonstrated. The basal caecal $\mathrm{I}_{\mathrm{sc}}$ in Group 2, mono-infected with C. jejuni, was statistically significantly higher $(p<0.05)$ than in Group 0 . After adding glucose and forskolin, the $\mathrm{I}_{\mathrm{sc}}$ in Group 2 continued to differ statistically significantly from Group 0 (Figures $1 \mathrm{~b}$ and 3; detailed data in Table S6). 


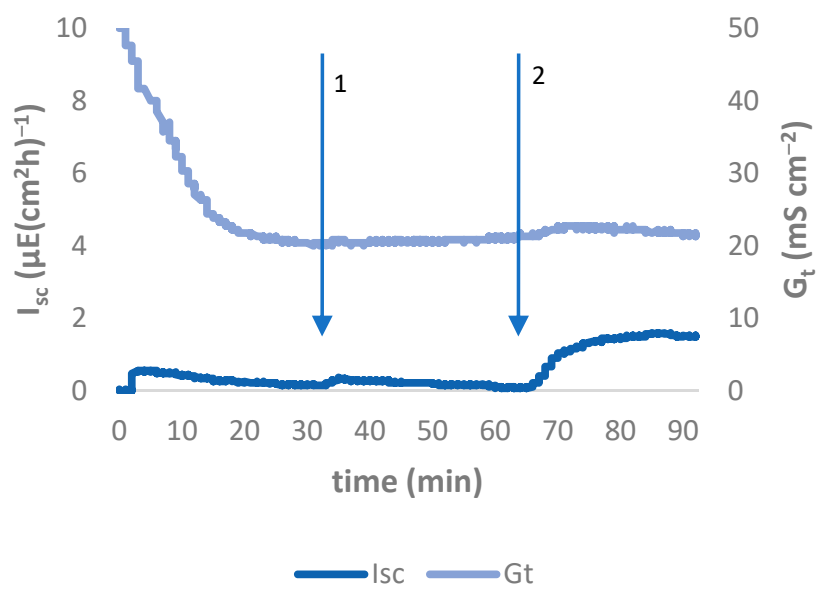

(a)

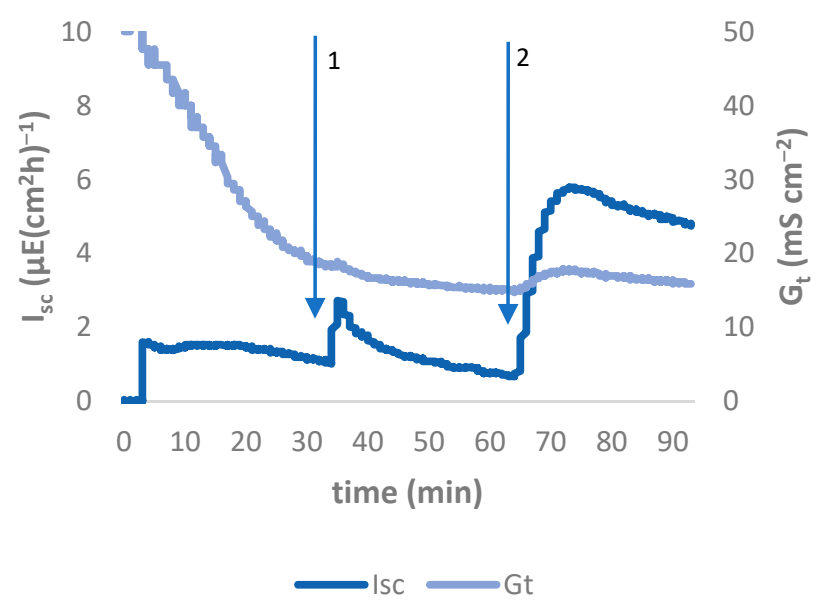

(c)

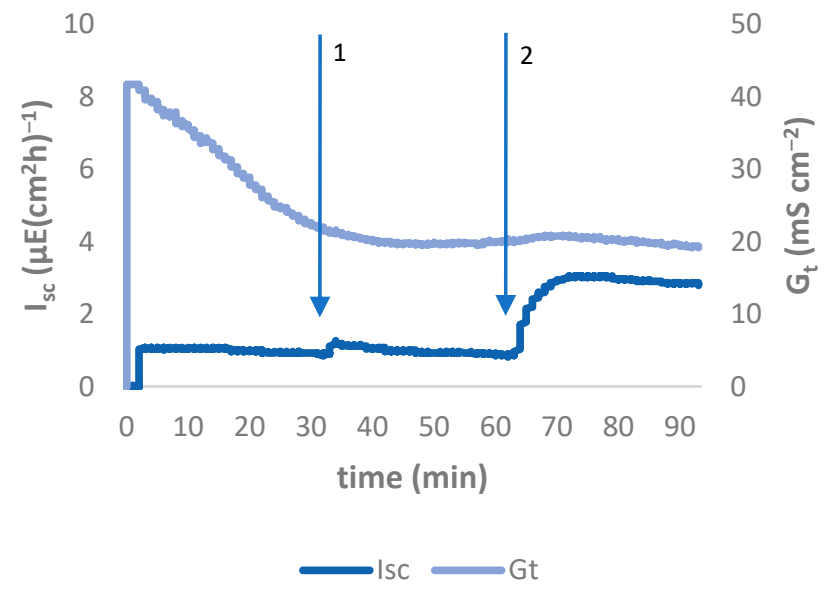

(b)

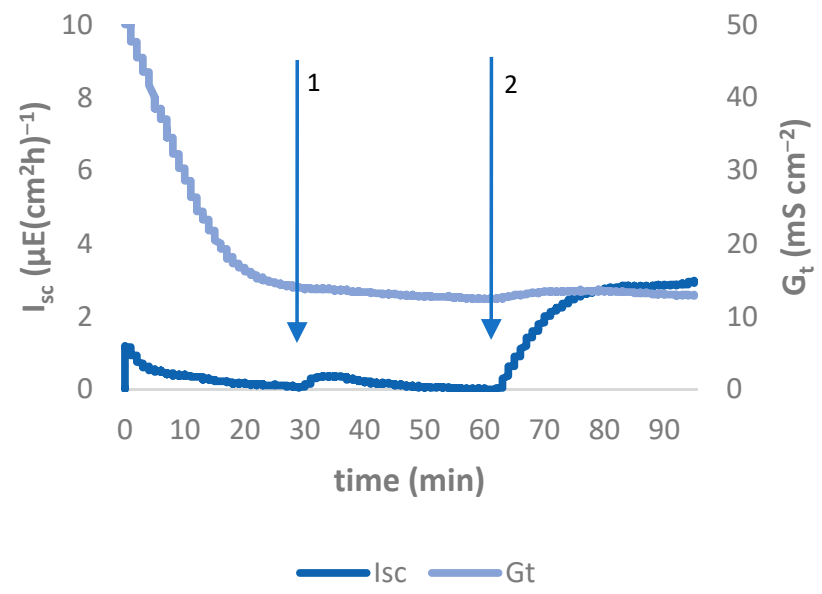

(d)

Figure 3. Time courses of $I_{s c}$ and $G_{t}$ in caecal tissue using Ussing chamber experiment of (a) Group 0, (b) Group 1, (c) Group 2, (d) Group 3. Arrows indicate addition of pharmaceuticals: 1 carbachol, 2 forskolin. The time course of the $\mathrm{I}_{\mathrm{sc}}$ of Group 2 (c) differs statistically significantly from Group $0(p<0.05)$.

\subsection{Conductance $\left(G_{t}\right)$ of Jejunal and Caecal Epithelia}

The basal $G_{t}$ values in jejunal and caecal samples did not differ statistically significantly between groups. The changes after adding glucose to the jejunal tissue and carbachol to the caecal tissue were also not statistically significantly different $(p>0.05)$. Accordingly, adding forskolin $30 \mathrm{~min}$ later did not result in statistically significant changes in the $G_{t}$ values $(p>0.05)$. A time course of the changes in the $\mathrm{G}_{\mathrm{t}}$-value in caecal tissue is shown in Figure 3 (detailed data in Tables S7 and S8).

\subsection{Results of the Histological Examination}

Almost all tissue samples of the intestinal sections (duodenum, jejunum, ileum, caecum, and colon) of all pigs were given the scores 1 or 2 in the applied scoring system, corresponding to a slight to mild neutrophilic and increased lymphoplasmacytic cell infiltration. Only two samples from the duodenum (both from Group 2) were found to have a score of 3. No statistically significant differences between the infected groups (Groups 1, 2, and 3 ) and the control group (Group 0$)$ were detected $(p>0.05)$. 


\subsection{Dry Matter of the Caecal Content}

Due to the differences between Group 2 and Group 0 in the tests using the Ussing chamber, a dry substance determination from the caecal content was carried out. Samples from each group were averaged and compared (Group 0: $143.52 \pm 17.68$; Group 1: $135.86 \pm 37.28$; Group 2: $108.87 \pm 17.23$; Group 3: $139.29 \pm 28.33$ ). The dry matter content of the caecum from Group 2 was statistically significantly lower than that from the control group $(p<0.05)$.

\section{Discussion}

The aim of this study was to evaluate whether colonisation of weaning pigs with different Campylobacter strains has an impact on intestinal health and mucosal barrier function.

Prerequisite for the Campylobacter infection model was the rearing of the piglets without infection with Campylobacter field strains, which was confirmed by the absence of Campylobacter spp. before inoculation and in the control group. In experiments with gnotobiotically reared piglets [9-11], a method for maintaining absence from Campylobacterstrains for days up to a few weeks was established in a highly sterile environment. In the present study, it was shown that Campylobacter-free rearing over a period of 12 weeks after Cesarean section is possible under strict hygiene standards without sterile conditions.

In previous studies, it was observed that a low infectious dose of $800 \mathrm{cfu}$ was sufficient to cause disease in $50 \%$ of the subjects in humans. At a dose of $10^{8}$, the disease rate was $100 \%[29,30]$.

An infectious dose of at least $10^{8} \mathrm{cfu}$ per animal was obtained. In previous studies, this infectious dose has been shown to be sufficient to achieve intestinal colonisation in pigs as safely as possible [28,31].

Although the piglets were assumed to have no maternal immunity against Campylobacter, comparable to colostrum-deprived or gnotobiotic piglets, none of them developed clinical signs throughout the experiment, but were successfully colonised. Furthermore, during post-mortem examination, internal organs did not show any gross lesions.

These observations are consistent with those of previous studies [28,31,32]. For the most part, Campylobacter spp. are considered commensals of the swine intestine [4]. Thus, as previously mentioned, it could be demonstrated, that Campylobacter spp. have no clinical effects on pigs. Therefore, the importance of Campylobacter infections in diarrhoel diseases of pigs can be neglected. However, when colonising gnotobiotic piglets with $C$. jejuni on the day of birth, significant clinical abnormalities were observed [9], comparable to other Campylobacter infection models with very young pigs $[10,11]$. In contrast to the histopathological results of the presented study, other trials with gnotobiotic piglets showed distinct histological alterations of the intestinal epithelium. These changes were described as an increase in mucous secretory cells, signs of villi shortening and blunting. In addition, some villous cells showed damaged nuclei and some crypt abscesses were present in the caecum $[9,10]$. These changes were not found in the present study. Thus, it seems that the intestine of gnotobiologically reared animals is more affected by Campylobacter spp. colonisation than is the case in animals that have not been kept under sterile conditions.

The Ussing chamber technique allows the measurement of the electrophysiological tissue parameters (conductance $\left(G_{t}\right)$ ) and short circuit current $\left(I_{s c}\right)$. In order to eliminate electrochemical gradients across the tissues, the experiments were performed under shortcircuited conditions, so that a change in short circuit current $\left(\mathrm{I}_{\mathrm{sc}}\right)$ implies a change in net transepithelial ion transfer. Additionally, tissue conductance $\left(\mathrm{G}_{t}\right)$ provides an indication of epithelial integrity [33].

Changes in short circuit currents depend on the transepithelial ion transport. Adding glucose to the mucosal side of jejunal samples stimulates the electrogenic SGLT1 transport system, resulting in an increase in $\mathrm{I}_{\mathrm{sc}}[22,23]$.

For caecal tissues, the addition of glucose was replaced by carbachol, since glucose is almost exclusively absorbed in the small intestine [23,34]. Forskolin and carbachol stimulate $\mathrm{Cl}^{-}$secretion: forskolin activates cAMP-controlled secretion [24] whereas carba- 
chol acts on Ca-controlled secretion [25-27]. This ion release into the intestinal lumen is always passively followed by $\mathrm{H}_{2} \mathrm{O}$. Thus, when the secretion of $\mathrm{Cl}^{-}$is increased, a greater amount of water is also released into the intestinal lumen. This manifests itself clinically as diarrhea [35].

It can be concluded that jejunal glucose transport by the secondary active co-transporter 1 (SGLT1 transport) [36,37] was not affected by Campylobacter colonisation. Similarly, cAMPmediated chloride secretion was not altered. The $\mathrm{I}_{\mathrm{sc}}$ increase from the jejunal epithelia was not statistically significantly different among all groups after adding forskolin $(p>0.05)$.

Microbiological investigation of ingesta showed that predominantly $C$. jejuni seems to colonise the jejunum, although $C$. coli was also detected, but to a lesser extent, which has also been demonstrated in a previous study [28]. Both agents did not affect the integrity of the studied intestinal barrier and the transport mechanisms.

Investigations on the caecal tissue showed that only Group 2 (mono-infected with C. jejuni) was found to differ statistically significantly from the control group in forskolinand carbachol-induced increases in $\mathrm{I}_{\mathrm{sc}}(p<0.05)$ due to an increased permeability for ions $\left(\mathrm{Cl}^{-}\right)$. Forskolin induces cAMP-regulated chloride secretion, whereas carbachol acts on calcium-regulated chloride secretion. In both mechanisms, water passively follows chloride into the intestinal lumen [27], initially causing a more fluid ingesta. Dry matter determination of caecal content confirmed these findings, although clinically, diarrohea could not be detected. One potential explanation for this fact might be that a substantial amount of water is reabsorbed along the intact colon [34], which could compensate the water loss in the caecum. The fact that the colon is an intestinal segment with a high water resorption rate has already been extensively described [34]. The mechanism of the caecal epithelium alteration remains unclear.

In connection with this, it can be speculated, that an infection with C. jejuni could have a subclinical effect on pigs and that the loss of water in the caecum could also have an influence on nutrient intake. This can lead to losses in performance and weight development, which could well be decisive in conventional pig farming. To be more precise, longer-term studies should be carried out to study the weight development of the pigs in more detail. In earlier experiments by Leonhard-Marek et al. [38], pigs were infected with parasites. It was found that chloride secretion was increased during the penetration phase of the parasites into the intestinal mucosa. It is possible that $C$. jejuni has a similar effect on the intestinal barrier, resulting in an increase in chloride secretion.

Despite the differences observed in the Ussing chamber experiments, corresponding histological changes could not be found, leading to the assumption that colonisation of C. jejuni affects the transport mechanisms of the intestinal mucosa without any inflammatory reaction. Van Deun et al. (2008) demonstrated in an in-vitro experiment that C. jejuni strains could invade chicken primary caecal epithelial crypt cells without showing any signs of necrosis or intestinal inflammation [39]. Transmigration might be possible by the cleavage of occludin, a tight junction protein impairing intestinal barrier function, which is assumed by Harrer et al. [40]. Further studies are needed to investigate the mechanism of Campylobacter spp. concerning disturbance of the intestinal barrier in swine. In addition, further studies should clarify whether the subclinical effect that the C. jejuni strain used in the present study has on pigs can be transferred to other C. jejuni strains or only applies to the one used here.

No significant increase in $\mathrm{I}_{\mathrm{SC}}$ was found either in mono-infected pigs with C. coli or in co-infected animals with C. coli and C. jejuni. A previous study by Leblanc et al. [32] proved that $C$. coli has a higher colonisation potential than $C$. jejuni in pigs. This could result in C. coli overriding $C$. jejuni colonisation in co-infection to the extent that a smaller amount of $C$. jejuni colonising the caecum did not have any impact on the intestinal transepithelial chloride transport. Enumeration of Campylobacter spp. in the ingesta may be able to substantiate this assumption. 


\section{Conclusions}

The results of the presented study demonstrate that the inoculated C. coli and C. jejuni strains of poultry origin are capable of colonising the intestine of weaned pigs and that both species integrated well after co-infection. The pigs did not show any clinical signs of disease after inoculation, although investigations using the Ussing chamber demonstrated an impact of $C$. jejuni on the caecal epithelium and the chloride transport mechanism. However, this effect appears to be compensated by the intact colon of the piglets so that no clinical disease occurs. Additionally, this study showed that the raising of Campylobacter free pigs is possible under high hygienic standards and that this pig colonisation trial seems to be suitable for studying Campylobacter infections without the need for gnotobiotic or specific-pathogen-free (SPF) animals.

Supplementary Materials: The following are available online at https:/ /www.mdpi.com/article/10 .3390/ani11092742/s1, Figure S1: Microbiological procedure for the detection of Campylobacter spp. in the fecal samples of the test animals on modified charcoal cefoperazonedeoxycholate agar plates (CCDA), Table S1: Ingredients of the nalidixic acid stock solution (1\%), Table S2: Ingredients of the streptomycin stock solution (1\%), Table S3: Quantity ratio for the preparation of the specific antibioticsCCDA agar with the respective stock solution (nalidixic acid or streptomycin sulphate), Table S4: Body temperature of the infection groups over the experimental period as mean + /- standard deviation (Group 0: $n=11$; Group 1: $n=8$; Group 2: $n=10$; Group 3: $n=8$ ), Table S5: $\Delta \mathrm{I}_{\mathrm{sc}}$ values for jejunal tissue, both basal values for the groups and the changes after addition of glucose and forskolin, the mean values and standard deviations for the respective groups (0-3) are shown (Group 0: $n=11$; Group 1: $n=8$; Group 2: $n=10$; Group 3: $n=8$ ), Table S6: $\Delta \mathrm{I}_{\mathrm{sc}}$ values for caecal tissue, both basal values for the groups and the changes after addition of carbachol and forskolin, the mean values and standard deviations for the respective groups (0-3) are shown (Group 0: $n=11$; Group 1: $n=8$; Group 2: $n=10$; Group 3: $n=8$ ), Table S7: $\Delta \mathrm{G}_{\mathrm{t}}$ values for jejunal epithelia, both basal values for the groups and the changes after addition of glucose and forskolin, the mean values and standard deviations for the respective groups (0-3) are shown (Group 0: $n=11$; Group 1: $n=8$; Group 2: $n=10$; Group 3: $n=8$ ), Table S8: $\Delta G_{t}$ values for caecal epithelia, both basal values for the groups and the changes after addition of carbachol and forskolin, the mean values and standard deviations for the respective groups (0-3) are shown (Group 0: $n=11$; Group 1: $n=8$; Group 2: $n=10$; Group 3: $n=8)$.

Author Contributions: A.R. performed the clinical trials and drafted the manuscript; K.-H.W. (deceased) participated in the design of the study; S.R. conceived and constructed the study; G.B. participated in the design of the study and helped to analyse and to interpret the data; M.H.-T. helped analyse and interpret the data; J.R. helped to draft the manuscript; A.v.A. conceived and constructed the study, participated in the clinical trial, and edited the manuscript. All authors have read and agreed to the published version of the manuscript.

Funding: Funded by the Deutsche Forschungsgemeinschaft (DFG, German Research Foundation) Projectnumber 411479547; supported by Deutsche Forschungsgemeinschaft and University of Veterinary Medicine Hannover, Foundation within the funding programme Open Access Publishing.

Institutional Review Board Statement: The study was conducted in accordance with the guidelines of the Declaration of Helsinki. Ethical authorization was granted following notification to the national veterinary authorities (33.9-42502-04-16/2132).

Data Availability Statement: The data presented in this study are available in Supplementary Material. Additional data are available on request from the corresponding author.

Acknowledgments: The authors would like to thank Marion Burmester and Hilke Bartels for their excellent technical support. We are also grateful to Saskia Neubert and Cornelia Schwennen for their great support given in conducting the experiments and for various other matters. We would like to thank Frances C. Sherwood-Brock, English Editorial Office, University of Veterinary Medicine Foundation Hannover, for her help in proofreading the manuscript. Lastly, our thanks go to Martin Beyerbach for his advice on statistical analysis. 
Conflicts of Interest: The authors declare no conflict of interest. The funders had no role in the design of the study; in the collection, analyses or interpretation of data; in the writing of the manuscript or in the decision to publish the results.

\section{References}

1. Taylor, D.N. Campylobacter Infections in Developing Countries, Campylobacter jejuni: Current Status and Future Trends; Nachamkin, I., Blaser, M.J., Tompkins, L.S., Eds.; American Society for Microbiology: New York, NY, USA, 1992; pp. 20-30.

2. Kirk, M.D.; Pires, S.M.; Black, R.E.; Caipo, M.; Crump, J.A.; Devleesschauwer, B.; Dopfer, D.; Fazil, A.; Fischer-Walker, C.L.; Hald, T.; et al. World Health Organization Estimates of the Global and Regional Disease Burden of 22 Foodborne Bacterial, Protozoal, and Viral Diseases, 2010: A Data Synthesis. PLoS Med. 2015, 12, e1001921.

3. Institut, R.K. Infectious Disease Epidemiology Yearbook of Notifiable Diseases for 2019. Available online: https://www.rki.de/ DE/Content/Infekt/Jahrbuch/Jahrbuecher/2019.html?nn=2374622 (accessed on 1 March 2020).

4. Harvey, R.B.; Young, C.R.; Ziprin, R.L.; Hume, M.E.; Genovese, K.J.; Anderson, R.C.; Droleskey, R.E.; Stanker, L.H.; Nisbet, D.J. Prevalence of Campylobacter spp isolated from the intestinal tract of pigs raised in an integrated swine production system. J. Am. Vet. Med. A 1999, 215, 1601-1604.

5. $\quad$ von Altrock, A.; Louis, A.L.; Rosler, U.; Alter, T.; Beyerbach, M.; Kreienbrocks, L.; Waldmann, K.H. The bacteriological and serological prevalence of Campylobacter spp. and Yersinia enterocolitica in fattening pig herds in Lower Saxony. Berl. Munch. Tierarztl. Wochenschr. 2006, 119, 391-399. [PubMed]

6. Hartung, M.; Alt, K.; Käsbohrer, A.; Tenhagen, B.-A. Pathogens Causing Zoonoses in Germany in 2016; Bundesinstitut für Risikobewertung: Berlin, Germany, 2019.

7. Ducluzeau, R. Implantation and development of the gut flora in the newborn animal. Ann. Rech. Vet. 1983, 14, 354-359. [PubMed]

8. Vítovec, J.; Koudela, B.; Štěrba, J.; Tomancová, I.; Matyáš, Z.; Vladík, P. The gnotobiotic piglet as a model for the pathogenesis of Campylobacter jejuni infection. Zent. Bakteriol. 1989, 271, 91-103. [CrossRef]

9. de Vries, S.P.; Linn, A.; Macleod, K.; MacCallum, A.; Hardy, S.P.; Douce, G.; Watson, E.; Dagleish, M.P.; Thompson, H.; Stevenson, A.; et al. Analysis of Campylobacter jejuni infection in the gnotobiotic piglet and genome-wide identification of bacterial factors required for infection. Sci. Rep. 2017, 7, 44283. [CrossRef]

10. Boosinger, T.R.; Powe, T.A. Campylobacter jejuni infections in gnotobiotic pigs. Am. J. Vet. Med. Res. 1988, 49, 456-458.

11. Babakhani, F.K.; Bradley, G.A.; Joens, L.A. Newborn piglet model for campylobacteriosis. Infect. Immun. 1993, 61, 3466-3475. [CrossRef]

12. Pielsticker, C.; Glunder, G.; Aung, Y.H.; Rautenschlein, S. Colonization pattern of C. jejuni isolates of human and avian origin and differences in the induction of immune responses in chicken. Vet. Immunol. Immunopathol. 2016, 169, 1-9. [CrossRef] [PubMed]

13. Humphrey, S.; Chaloner, G.; Kemmett, K.; Davidson, N.; Williams, N.; Kipar, A.; Humphrey, T.; Wigley, P. Campylobacter jejuni is not merely a commensal in commercial broiler chickens and affects bird welfare. mBio 2014, 5, e01364-01314. [CrossRef] [PubMed]

14. Hofreuter, D.; Novik, V.; Galan, J.E. Metabolic diversity in Campylobacter jejuni enhances specific tissue colonization. Cell Host Microbe 2008, 4, 425-433. [CrossRef] [PubMed]

15. Dasti, J.I.; Tareen, A.M.; Lugert, R.; Zautner, A.E.; Gross, U. Campylobacter jejuni: A brief overview on pathogenicity-associated factors and disease-mediating mechanisms. Int. J. Med. Microbiol. 2010, 300, 205-211. [CrossRef]

16. Alemka, A.; Corcionivoschi, N.; Bourke, B. Defense and adaptation: The complex inter-relationship between Campylobacter jejuni and mucus. Front. Cell Infect. Microbiol. 2012, 2, 15. [CrossRef]

17. van Vliet, A.H.; Ketley, J.M. Pathogenesis of enteric Campylobacter infection. J. Appl. Microbiol. 2001, 90, 45S-56S. [CrossRef] [PubMed]

18. MacCallum, A.; Hardy, S.P.; Everest, P.H. Campylobacter jejuni inhibits the absorptive transport functions of Caco-2 cells and disrupts cellular tight junctions. Microbiology 2005, 151, 2451-2458. [CrossRef] [PubMed]

19. Chen, M.L.; Ge, Z.; Fox, J.G.; Schauer, D.B. Disruption of tight junctions and induction of proinflammatory cytokine responses in colonic epithelial cells by Campylobacter jejuni. Infect. Immun. 2006, 74, 6581-6589. [CrossRef] [PubMed]

20. Awad, W.A.; Molnar, A.; Aschenbach, J.R.; Ghareeb, K.; Khayal, B.; Hess, C.; Liebhart, D.; Dublecz, K.; Hess, M. Campylobacter infection in chickens modulates the intestinal epithelial barrier function. Innate Immun. 2015, 21, 151-160. [CrossRef]

21. Awad, W.A.; Aschenbach, J.R.; Ghareeb, K.; Khayal, B.; Hess, C.; Hess, M. Campylobacter jejuni influences the expression of nutrient transporter genes in the intestine of chickens. Vet. Microbiol. 2014, 172, 195-201. [CrossRef]

22. Schenke, K. Functional and Molecular Studies of Glucose Transport in the Porcine Proximal Jejunum; Freie Universität Berlin: Berlin, Germany, 2014.

23. Klinger, S.; Lange, P.; Brandt, E.; Hustedt, K.; Schroder, B.; Breves, G.; Herrmann, J. Degree of SGLT1 phosphorylation is associated with but does not determine segment-specific glucose transport features in the porcine small intestines. Physiol. Rep. 2018, 6, e13562. [CrossRef]

24. Seamon, K.B.; Padgett, W.; Daly, J.W. Forskolin: Unique diterpene activator of adenylate cyclase in membranes and in intact cells. Proc. Natl. Acad. Sci. USA 1981, 78, 3363-3367. [CrossRef] [PubMed]

25. Chandan, R.; Hildebrand, K.R.; Seybold, V.S.; Soldani, G.; Brown, D.R. Cholinergic neurons and muscarinic receptors regulate anion secretion in pig distal jejunum. Eur. J. Pharmacol 1991, 193, 265-273. [CrossRef] 
26. Bronsveld, I.; Mekus, F.; Bijman, J.; Ballmann, M.; Greipel, J.; Hundrieser, J.; Halley, D.J.; Laabs, U.; Busche, R.; De Jonge, H.R.; et al. Residual chloride secretion in intestinal tissue of deltaF508 homozygous twins and siblings with cystic fibrosis. The European CF Twin and Sibling Study Consortium. Gastroenterology 2000, 119, 32-40. [CrossRef]

27. Barrett, K.E.; Keely, S.J. Chloride secretion by the intestinal epithelium: Molecular basis and regulatory aspects. Annu. Rev. Physiol. 2000, 62, 535-572. [CrossRef]

28. Nommensen, G. Studies on the Invasion and Colonization Behavior of Campylobacter Jejuni and Campylobacter Coli Strains of Different Origin in the Göttingen Minipig; University of Veterinary Medicine Hannover, Foundation: Hannover, Germany, 2014.

29. Black, R.E.; Levine, M.M.; Clements, M.L.; Hughes, T.P.; Blaser, M.J. Experimental Campylobacter jejuni infection in humans. J. Infect. Dis. 1988, 157, 472-479. [CrossRef] [PubMed]

30. Cawthraw, S.A.; Wassenaar, T.M.; Ayling, R.; Newell, D.G. Increased colonization potential of Campylobacter jejuni strain 81116 after passage through chickens and its implication on the rate of transmission within flocks. Epidemiol. Infect. 1996, 117, 213-215. [CrossRef]

31. Bratz, K.; Bucker, R.; Golz, G.; Zakrzewski, S.S.; Janczyk, P.; Nockler, K.; Alter, T. Experimental infection of weaned piglets with Campylobacter coli-excretion and translocation in a pig colonisation trial. Vet. Microbiol. 2013, 162, 136-143. [CrossRef]

32. Leblanc Maridor, M.; Denis, M.; Lalande, F.; Beaurepaire, B.; Cariolet, R.; Fravalo, P.; Federighi, M.; Seegers, H.; Belloc, C. Experimental infection of specific pathogen-free pigs with Campylobacter: Excretion in faeces and transmission to non-inoculated pigs. Vet. Microbiol. 2008, 131, 309-317. [CrossRef] [PubMed]

33. Clarke, L.L. A guide to Ussing chamber studies of mouse intestine. Am. J. Physiol. Gastrointest. Liver Physiol. 2009, 296, G1151-G1166. [CrossRef] [PubMed]

34. Lærke, H.N.; Hedemann, M.S. The digestive system of the pig. In Nutritional Physiology of Pigs—Online Publication; Bach Knudsen, K.E., Kjeldsen, N.J., Poulsen, H.D., Jensen, B.B., Eds.; Videncenter for Svineproduktion: Copenhagen, Denmark, 2012.

35. Leonhard-Marek, S.; Hempe, J.; Schroeder, B.; Breves, G. Electrophysiological characterization of chloride secretion across the jejunum and colon of pigs as affected by age and weaning. J. Comp. Physiol. B 2009, 179, 883-896. [CrossRef] [PubMed]

36. Wright, E.M.; Hirayama, B.A.; Loo, D.F. Active sugar transport in health and disease. J. Intern. Med. 2007, 261, 32-43. [CrossRef] [PubMed]

37. Wright, E.M.; Hirsch, J.R.; Loo, D.D.; Zampighi, G.A. Regulation of Na+/glucose cotransporters. J. Exp. Biol. 1997, 200, 287-293. [CrossRef] [PubMed]

38. Leonhard-Marek, S.; Daugschies, A. Electro- and Transport-physiological Changes in Pig Proximal Colon during Parasitic Infection. Comp. Biochem. Physiol. 1997, 118, 345-347. [CrossRef]

39. Van Deun, K.; Pasmans, F.; Ducatelle, R.; Flahou, B.; Vissenberg, K.; Martel, A.; Van den Broeck, W.; Van Immerseel, F.; Haesebrouck, F. Colonization strategy of Campylobacter jejuni results in persistent infection of the chicken gut. Vet. Microbiol. 2008, 130, 285-297. [CrossRef] [PubMed]

40. Harrer, A.; Bücker, R.; Boehm, M.; Zarzecka, U.; Tegtmeyer, N.; Sticht, H.; Schulzke, J.D.; Backert, S. Campylobacter jejuni enters gut epithelial cells and impairs intestinal barrier function through cleavage of occludin by serine protease HtrA. Gut Pathog. 2019, 11, 1-16. [CrossRef] [PubMed] 